
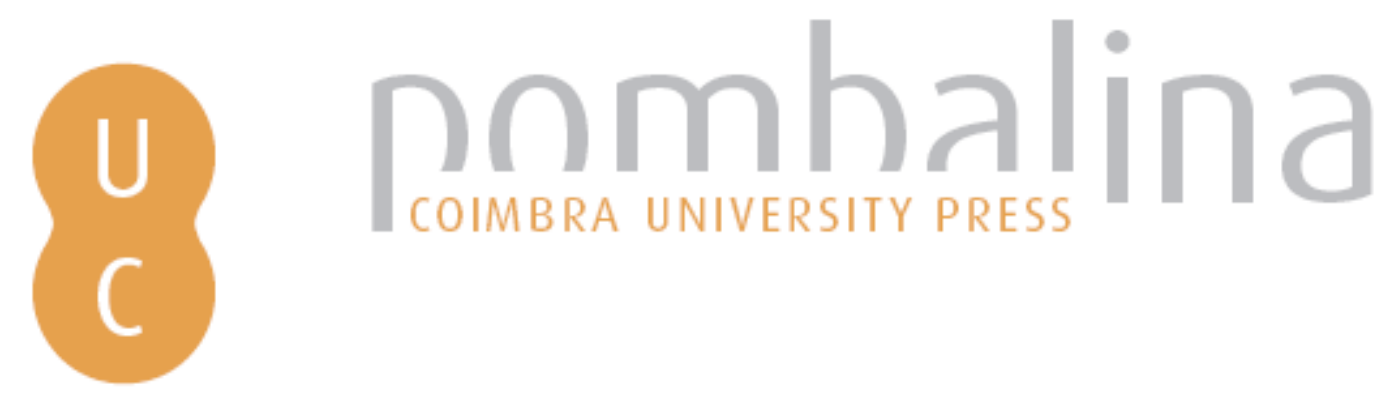

O impacto das bibliotecas digitais de patentes no processo de inovação em Portugal

Autor(es): $\quad$ Maravilhas, Sérgio; Borges, Maria Manuel

Publicado por: Imprensa da Universidade de Coimbra

URL

persistente: URI:http://hdl.handle.net/10316.2/31883

DOI: $\quad$ DOI:http://dx.doi.org/10.14195/978-989-26-0869-3_4

Accessed : $\quad$ 26-Apr-2023 11:44:07

A navegação consulta e descarregamento dos títulos inseridos nas Bibliotecas Digitais UC Digitalis, UC Pombalina e UC Impactum, pressupõem a aceitação plena e sem reservas dos Termos e Condições de Uso destas Bibliotecas Digitais, disponíveis em https://digitalis.uc.pt/pt-pt/termos.

Conforme exposto nos referidos Termos e Condições de Uso, o descarregamento de títulos de acesso restrito requer uma licença válida de autorização devendo o utilizador aceder ao(s) documento(s) a partir de um endereço de IP da instituição detentora da supramencionada licença.

Ao utilizador é apenas permitido o descarregamento para uso pessoal, pelo que o emprego do(s) título(s) descarregado(s) para outro fim, designadamente comercial, carece de autorização do respetivo autor ou editor da obra.

Na medida em que todas as obras da UC Digitalis se encontram protegidas pelo Código do Direito de Autor e Direitos Conexos e demais legislação aplicável, toda a cópia, parcial ou total, deste documento, nos casos em que é legalmente admitida, deverá conter ou fazer-se acompanhar por este aviso. 
Maria Manuel Borges

Elias Sanz Casado

Coordenação

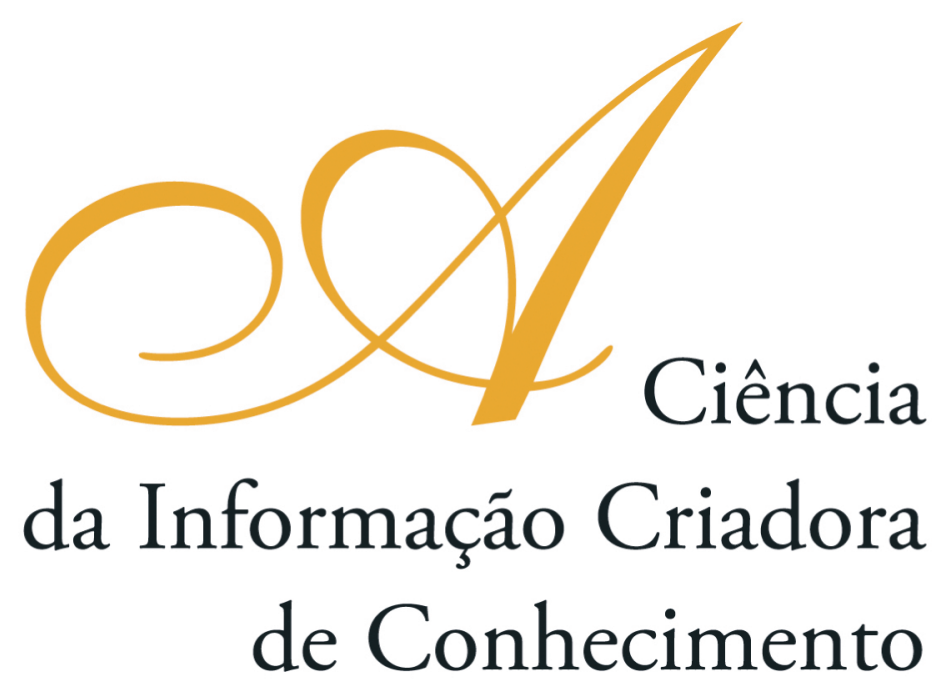

Vol. I I

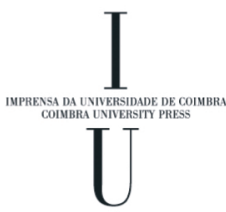

- COImbra 2009 


\title{
O Impacto das Bibliotecas Digitais de Patentes no Processo de Inovação em Portugal ${ }^{\mathrm{I}}$
}

\author{
Sérgio Maravilhas \\ Universidade de Aveiro (Portugal) \\ Maria Manuel Borges \\ Universidade de Coimbra (Portugal)
}

\section{Resumo}

A Informação é um recurso indispensável ao funcionamento e sobrevivência das organizaçôes. Para que as organizaçôes possam competir no ambiente global, de rápidas mudanças, onde se inserem, necessitam de obter informação que lhes permita inovar e adquirir vantagens competitivas nos mercados em que actuam. A informação associada à Propriedade Industrial, designada por Informação de Patentes, proporciona uma crescente competitividade através da transferência de tecnologia que motiva e revela-se de extrema importância económica pela inovação que incentiva.

Após a análise de vários Indicadores e de Estudos Nacionais e Internacionais, constata-se que Portugal não está a utilizar satisfatoriamente os recursos dos registos de Propriedade Industrial, não retirando daí as vantagens que lhe poderia propiciar. Os dados publicados indiciam que os Centros de investigação universitários não estão a rentabilizar as suas potencialidades no que respeita à utilização deste tipo de informação que poderia, se devidamente integrado nos projectos de investigação, motivar mais Inovação, mais vantagem competitiva e, também, maior número de registos de PI, originando mais empresas e maior crescimento económico. Sustenta-se que uma utilização coerente e efectiva das Bibliotecas Digitais de Patentes, contendo informaçáo resultante das actividades de I\&D com aplicação industrial, pode contribuir para o aumento da criatividade e suporte na resolução de problemas de investigaçáo, potenciando a inovação através de novos produtos e processos daí decorrentes. O presente trabalho procura responder à questão sobre a relação entre o grau de conhecimento e nível de utilizaçáo das bibliotecas digitais de patentes pelos centros de investigação em Portugal e o seu contributo para o processo de inovação. A hipótese de trabalho que procuraremos validar é de que os Centros de Investigaçáo Universitários que conhecem e utilizam mais a Informaçáo constante nas BDP são mais inovadores, patenteiam mais invençôes, geram mais produtos e processos novos, originando mais 'spin-offs' para a sua aplicação industrial.

\section{Abstract}

Information is an essential resource to the functioning and survival of organizations. In order for organizations to compete in a global environment, with rapid changes, where they move nowadays, they need to obtain information that'll allow them to innovate and acquire

\footnotetext{
${ }^{1}$ Este trabalho resulta da investigação para um programa doutoral orientado pela co-autora, Profa. Maria Manuel Borges da U.C. e co-orientado pela Profa. Fernanda Ribeiro da U.P.
} 
competitive advantages in the markets they operate in. Scientific and technical information associated to Industrial Property - Patent Information - can provide further competitiveness through the transfer of technology that it motivates and is of vital economic importance due to the innovation that it stimulates.

After analysing several Indicators, National and International Studies, we realized that Portugal is not using the resources of the Industrial Property's records in a satisfactory way, not taking advantage of its benefits. The data published shows that university research centres are not living up to their full potential when it comes to using this type of information since it could, when due integrated into research projects, motivate innovation, provide competitive advantages, and increase the number of IP records. This could lead to an increase of the number of new companies and to economic growth. We support that a coherent and effective use of Patent Digital Libraries that contain information resulting from R\&D activities with industrial applications can contribute to the increase of creativity and support problemsolving in research, developing innovation through the resulting new products and processes. This research attempts to answer the question about the relationship between the degree of knowledge and level of usage of Patent Digital Libraries by research centres in Portugal and their contribution to the innovation process. The hypothesis to validate is that University Research Centres that know and use the information in the PDL are more innovative since they contribute with more patents and they generate more new products and processes, giving birth to more spin-offs with industrial applications.

\section{Introdução}

A Informação é um recurso indispensável ao funcionamento e sobrevivência das organizaçóes.

$\mathrm{Na}$ economia actual a riqueza gera-se através da criação de valor usando o conhecimento que provém de ideias inovadoras. Gerindo eficazmente a informação as ideias para futuros negócios emergem, dando origem a inovaçôes que podem traduzirse em vantagens competitivas para os seus detentores.

Pretende-se demonstrar que tal sucede com a utilização de um tipo de informação em particular, a saber, a Informação de Patentes.

Após a análise de vários Indicadores e de Estudos Nacionais e Internacionais, constata-se que Portugal não está a utilizar de forma satisfatória os recursos dos registos de Propriedade Industrial, náo retirando daí as vantagens que lhe poderia propiciar.

Os dados publicados (Roland Berger \& Partner, 1998; Motivaction, 2003; Godinho, 2003) indiciam que os centros de investigação universitários não estão a rentabilizar as suas potencialidades no que respeita à utilização deste tipo de informação que poderia, se devidamente integrado nos projectos de investigação, motivar mais Inovação, mais vantagem competitiva e, também, maior número de registos de PI, originando mais empresas e maior crescimento económico. ${ }^{2}$

\footnotetext{
2 "Se na União Europeia os dados indicam 30\% de redundância na investigação, em Portugal o valor sera certamente superior. (...) Estamos a falar de um desperdicio de cerca de 372 milhöes de euros, porque utilizados em pesquisa científica que, por não ser original, não pode ser explorada comercialmente. E, muitas vezes, lembrou Ana Casaca, o investigador só dá conta disso mesmo quando procura os agentes oficiais para o registo da propriedade intelectual. A única maneira de evitar essa situação, defende a directora, num ambiente global em que todos os anos são publicados um milhão de novos documentos de patentes, é através de um trabalho de
} 
Uma das prerrogativas para que a Patente possa ser concedida, é que a informação constante do pedido de Patente seja de tal forma detalhada que uma pessoa versada na área seja capaz, ela própria, de executar o invento. A finalidade da sua divulgação visa catalisar a actividade inventiva de outros, tornando possível o avanço da tecnologia que, de outra forma, continuaria a ser mantida em segredo.

A maior parte da informação contida nos documentos de Patente não está publicada em nenhum outro lugar, tornando as Patentes uma fonte de informação única e essencial para conhecer novas informaçôes técnicas.

Segundo dados da $\mathrm{OMPI}^{3}$, existem actualmente mais de 70 milhóes de Patentes atribuídas em todo o Mundo sendo em média efectuados um milhão de novos pedidos todos os anos. Tal quantidade de documentos torna a Literatura de Patentes a maior fonte de informação tecnológica disponível em todo o mundo, sendo o maior repositório de conhecimento técnico, possuidor de um valor incalculável.

Constatando-se esta relação entre Informação de Patentes e vantagens competitivas promovidas pelas inovaçóes produzidas, torna-se imperioso formular uma estratégia que permita às Organizaçóes portuguesas usufruírem ao máximo das vantagens da utilização dessa informação ${ }^{4}$. Para isso, será necessário um esforço de divulgação dessas vantagens, como também fomentar o efectivo acesso a esse manancial de informação de forma a poder ser utilizado na geraçáo de conhecimentos novos que se traduzam em aplicaçôes concretas (Godinho, 2003, p. 28-29).

Começamos por explicar o que é a Informaçáo de Patentes, a sua origem e proveniência, formas de utilização como fonte de informação científico-técnica e meio de realização de vigilância tecnológica. Alguns exemplos de utilização como meio de obtenção de vantagens competitivas serão dados a conhecer, como também alguns dos recursos disponíveis gratuitamente a partir de sítios na Internet que possibilitam o acesso a diversas Bibliotecas Digitais de Patentes, mostrando porque se revelam de extraordinária importância para o tema em análise. Num momento seguinte fazemos uma breve alusão às Bibliotecas Digitais, após o que passamos a explicar o que são Patentes de Invenção e como podem ser usadas para salvaguardar os resultados dos trabalhos de investigação. Também mostramos como podem ser usadas estas informaçóes sem infringir os direitos e salvaguardas dos seus detentores.

Passamos, em seguida, a descrever os aspectos metodológicos do nosso trabalho, descrevendo a Questão de Investigação e os Objectivos de Investigação que nos propomos atingir. Descrevemos os instrumentos de recolha de dados que serão utilizados e respectivos objectivos.

inteligência tecnológica que seja capaz de organizar e analisar a informação existente nas bases de dados de patentes de todo o mundo. Uma ferramenta de gestão que pode ser ainda utilizada, de forma preventiva, para a selecção das linhas de investigação a serem apoiadas pelo Estado. Um método que, segundo Ana Casaca, já está a ser usado em Espanha para a avaliação de candidaturas a financiamento público. (...) € 32 mil milhóes: Diz o European Patent Office que esse é o valor gasto pelas empresas da U.E. em investigação redundante." (Ribeiro, D., 2007, p. 34).

3 http://www.wipo.int - 21-02-2008.

4 "(...) Large corporations turn to patent information for the purpose of competitor intelligence, market analysis and forecasting, current awareness, R\&D, infringement avoidance, and other reasons." (BUTLER, 1995 , p. 82). 
Concluímos com uma síntese de tudo que foi descrito e analisado ao longo do trabalho, salientando algumas ideias que podem ser utilizadas para rentabilizar os resultados de projectos de investigação, transformando-os em inovaçôes que podem originar Spin-offs para a sua exploração comercial.

\section{1 - A Informação de Patentes}

\section{1 - Definição e origem}

"Necessity is the mother of invention"

Para obter a protecção por Patente, o requerente deve formalizar um pedido junto do INPI, OMPI ou EPO, juntamente com a revelação e descrição total dos detalhes da sua invenção, acompanhada de uma série de Reivindicaçôes, que constituem o cerne da própria invenção e a matéria para a qual se visa obter a protecção legal. No decurso do processo de registo e concessão da Patente, os gabinetes oficiais como o INPI, EPO ou $\mathrm{OMPI}^{5}$, irão gerar um ou mais documentos de índole legal que se designam por Literatura de Patentes. A informação que estes documentos contêm designa-se por Informação de Patentes. Após a publicação do pedido de Patente essa informação passa a ser de acesso público para quem a desejar consultar. Em suma, em troca da protecção por Patente concedida para o seu invento por 20 anos $^{6}$, a informação referente à invenção passará a ser de domínio público, podendo essas invençôes ser realizadas para fins de investigação.

A finalidade desta divulgação visa catalisar a actividade inventiva de outros, tornando possível o avanço da tecnologia que, de outra forma, continuaria a ser mantida em segredo.

Uma das prerrogativas para que a Patente possa ser concedida, é que a informação constante do pedido de Patente seja de tal forma detalhada que uma pessoa versada na área seja capaz ela própria de executar o invento.

A maior parte da informaçáo contida nos documentos de Patente não está publicada em nenhum outro lugar, tornando as Patentes uma fonte de informaçáo única e essencial para conhecer novas informaçóes técnicas.

Existem inúmeros exemplos que mostram lapsos de vários anos desde que a invenção é patenteada até que seja divulgada publicamente por outros meios, sendo a documentação de patentes o único lugar onde esta pode ser encontrada antes de ser dada a conhecer pelo seu detentor. Na Tabela 1 são apresentados exemplos conhecidos, em que a invenção foi divulgada pelas patentes com anos de antecedência em relação a outras fontes.

\footnotetext{
${ }^{5}$ No caso de se requerer protecção via Patent Cooperation Treaty - PCT.

${ }^{6}$ Excepto os medicamentos e produtos fitofarmacêuticos cujo Certificado Complementar de Protecção (CCP) amplia esse prazo por mais 5 anos.
} 
Tabela 1 - Actualidade da Informação Patentária (OMPI, 1982. Apud Macedo \& Barbosa, 2000, p.58)

\begin{tabular}{|l|l|l|l|}
\hline Inventor & Invençáo & Patente: ano de publicação & Ano outras publicaçōes \\
\hline Hollerith & Cartão perfurado & 1889 & 1914 \\
\hline Baird & Televisão & 1923 & 1928 \\
\hline Whittle & Turboreactor & 1936 & 1946 \\
\hline Morrogh & Ferro fundido dúctil & 1939 & 1947 \\
\hline Ziegler, N. & Catalisadores de polimerização & 1953 & 1960 \\
\hline
\end{tabular}

Acrescente-se a esta lista o Motor a jacto que foi descrito por este meio cerca de 10 anos antes de ter sido conhecido através de outras fontes. ${ }^{7}$

Muitos documentos de patente cuja validade legal já expirou, podem conter informaçóes técnicas valiosas que na altura estavam à frente do seu tempo, sem meios de serem efectivamente realizadas em termos técnico-industriais ou económicos, ou para as quais os consumidores não estavam ainda preparados.

Além da informação técnica contida nos documentos de Patente, referente à invenção em si, outra fonte de informação importante, que normalmente é descurada, são os Relatórios de Pesquisa ${ }^{8}$. O Relatório de Pesquisa é proporcionado pelo Gabinete de Patentes onde se requereu o registo e é constituído por uma lista de todas as Patentes, Livros, Artigos de Jornal e de Revista, Actas de Conferências, Teses, etc., que possam ter alguma relação com o invento em questão.

Também se devem ter em atenção as Referências e Citações realizadas no pedido de Patente pelo requerente pois permitem situar em que grau de desenvolvimento se encontra a área tecnológica onde se integra o invento.

Todas estas informaçóes estão, actualmente, pesquisáveis a partir de $\mathrm{BD}$ on line, através de sítios na Internet.

Para Idris (2003), as principais razóes para analisar a Informação de Patentes são: (i) A informação actualizada contida nos documentos de Patentes pode ajudar a evitar investimentos erróneos relativamente à possibilidade de duplicar trabalhos de pesquisa que já foram realizados; (ii) $\mathrm{O}$ uso insuficiente da Informação de Patentes tem causado um desperdício considerável de fundos investidos em programas de I\&D cujo retorno está ameaçado pela existência de tecnologia patenteada; (iii) Em certas circunstâncias, é possível utilizar a Informação de Patentes para desenvolver novos produtos e processos.

Por exemplo, a Unilever desenvolveu a Ceramides e patenteou a sua utilização para um grande número de aplicaçóes. Contudo, não registou a patente para a aplicação da tecnologia aos champôs, que foi posteriormente concedida a um concorrente (Tidd, J., Bessant, J. \& Pavitt, K., 2003, p. 187).

Marcus (1995) afirma que, para além dos parâmetros óbvios que se podem encontrar na Informação de Patentes, tais como, a) Nome do inventor, b) Detentor da Patente, c)

\footnotetext{
7 Cf. http://www.wipo.int

${ }^{8}$ Usualmente são disponibilizados aquando da publicação da Patente, constando na primeira página no caso das Patentes concedidas pelo USPTO, ou nas páginas finais no caso do EPO e PCT.
} 
Datas de prioridade, d) Família de Patentes, etc., se o pesquisador usar a sua imaginação pode encontrar uma enorme variedade de informaçóes comercialmente valiosas, como: (i) Possibilidade de encontrar ou identificar potenciais clientes ou parceiros de negócio;

(ii) Proporcionar informação de suporte a uma reunião de negócios, permitindo ficar a conhecer o potencial técnico da empresa com quem se vai reunir; (iii) Identificar tendências em I\&D, novas tecnologias e novos produtos; (iv) Identificar tendências e movimentaçóes entre empresas, podendo indiciar fusóes e aquisiçóes; (v) Facilitar a transferência de tecnologia ou o licenciamento de tecnologia, permitindo adquirir o que a empresa necessita ou vender o que a empresa desenvolveu; (vi) Prevenir a duplicaçáo de projectos de I\&D, evitando a cópia; (vii) Identificar especialistas num determinado campo tecnológico ou área científica; (viii) Estabelecer novas aplicaçôes e utilizaçôes para produtos e tecnologias existentes; (ix) Encontrar soluçôes para problemas técnicos; (x) Apoiar a geração de ideias para novos produtos ou processos; (xi) Identificar tendências de Marketing; (xii) Estabelecer a data de expiração de uma Patente, que permitirá a livre utilização dessa invenção; (xiii) Identificar potenciais concorrentes; (xiv) Monitorizar as actividades dos concorrentes; (xv) Estabelecer o 'estado-da-arte' da técnica. (Marcus, D. C., 1995, p. 65-66).

\section{2 - Exemplos de Utilização da Informação de Patentes}

"We can't prevent what we can't predict"

Tendo em conta que a maioria das patentes existentes em todo o mundo já expirou, tendo terminado a sua protecção, não deixa de ser importante consultar esses documentos que, apesar de caducados em termos legais, continuam a conter em si importante informação técnica. ${ }^{9}$

Em termos industriais e empresariais, existem um sem número de invençôes que não estão a ser exploradas comercialmente ou estão a ser sub-exploradas.

A survey reported that $67 \%$ of US companies own technology assets that they fail to exploit (assessed at between US\$115 billion to US\$ 1 trillion). It estimates that about US\$ 100 billion is tied up in such idle innovation within the IP portfolios of big companies. (BTG International (technology transfer firm) survey, 1998. As cited in Idris, K., 2003, p. 92).

Começaremos pelo exemplo do Velcro, nome comercial de um conhecido material usado para substituir botóes ou fechos de correr. O Velcro foi inventado em 1948 por Georges de Mestral, engenheiro suíço, que obteve a patente para esse invento em 1957. Nessa época, a única organização que demonstrou algum interesse no invento foi a

9 "An example of the use of patent information to locate existing technology which can be used in a new context: Industrial Copolymers Ltd. won a Smart achievement award for a product for waterproofing a roof. An improvement on conventional techniques using three layers of bitumen felt, the product is a formulation including a specific additive which develops a high build, high film thickness coating. The additive used, oxazolidine, was spotted in a 20-year old patent as a potential candidate to achieve this, even though it had been little used in the $U K$ in the intervening years. The coatings are also well-suited to related waterproofing applications such as the treatment of bridges and of car-park decking". (SLATER, P., TWYMAN, P.\& BLACKMAN, M., 2000, p. 340). 
NASA que o utilizou nos fatos espaciais dos seus astronautas. Actualmente, apesar da sua patente estar caducada, é amplamente utilizado no mesmo tipo de aplicaçóes demonstrando que existem produtos que continuam a ter aplicaçáo industrial vários anos após expirado o período de protecção da patente não recebendo, actualmente, o seu inventor qualquer compensação monetária pela sua invenção.

Outro exemplo conhecido é o caso do Nylon, polímero sintético de grande aplicação em fibras têxteis, que se caracteriza por ser extremamente resistente e de grande elasticidade. Este produto foi desenvolvido na década de 30 do século XX por um grupo de cientistas dirigido pelo químico Wallace Carothers da empresa DuPont, nos EUA. Ainda hoje se utiliza o Nylon em artigos tão variados como, lingerie, camisas, gabardinas, pára-quedas, linha cirúrgica, linha e redes de pesca e, se moldado, em utensílios de cozinha e peças de máquinas industriais. Contudo, a sua tecnologia tem cerca de 70 anos e a sua patente está caducada. O mesmo acontece com a Lycra, Terylene, PVC e outros produtos sintéticos.

Outro exemplo, bem utilizado em Portugal, diz respeito aos medicamentos genéricos. Estes são a substância activa de determinado medicamento cuja patente expirou, passando assim a ser de domínio público, passível de ser fabricado e comercializado por qualquer outra empresa, desde que não utilize a marca comercial registada, se ainda em vigor, pelo proprietário da patente caducada.

O caso que passamos a descrever é o do antibiótico mais comercializado em todo o mundo: a Azithromycina. ${ }^{10}$ Patenteado por uma empresa croata de nome Pliva, a maior farmacêutica da Europa Central, esta substância estava a ser explorada apenas a nível local, estando o seu potencial de mercado 'adormecido'. Os cientistas da Pfizer, encontraram a sua descriçáo quando pesquisavam documentos de patente, reconhecendo de imediato as potencialidades que se lhes ofereciam caso pudessem obter a Licença para a sua exploração. Estava-se no ano de 1981 e a patente tinha sido registada em 1980 pela Pliva. Tal significa que a consulta da Informação de Patentes possibilitou à Pfizer uma clara liderança de mercado no ramo dos antibióticos, concedendo-lhe uma vantagem competitiva, e possibilitou à Pliva lucros fenomenais derivados dos acordos de Licenciamento concedidos à Pfizer que lhe possibilitaram expandir-se não só na Croácia como também na Polónia e na Rússia.

Sales of Zithromax ${ }^{T M}$ exceeded US\$ 1 billion last year and are expected to grow. (Wall Street Journal (Brussels), March 3, 1999, p. 14. As cited in Idris, K., 2003, p. 91).

Outro produto bem conhecido é o Aspartame, adoçante artificial desenvolvido pela Searle, empresa posteriormente adquirida pela Monsanto, sendo comercializado com a marca comercial Nutrasweet. Cerca de 200 vezes mais doce do que a sacarose ou açúcar de cana, é utilizado em refrigerantes, sobremesas e como adoçante de mesa. Graças à Informação de Patentes qualquer empresa interessada poderia ficar a saber que a sua patente caducou em 1992, o que significa que pode ser fabricado e comercializado sob qualquer outra designação comercial.

Outra vantagem proporcionada pela Informação de Patentes é a utilização de tecnologias para a resolução de problemas de áreas distintas daquelas para que foram

\footnotetext{
${ }^{10}$ Apesar da substância activa que constitui o medicamento ter sido denominada azithromycina, este é conhecido comercialmente sob a marca registada $Z_{i t h r o m a x}{ }^{\mathrm{TM}}$.
} 
patenteados, conforme se ilustra pelo exemplo seguinte: a fábrica Cosworth, de motores de alto desempenho, adaptou uma invenção de uma bomba electromagnética oriunda da área da energia nuclear, para forçar o metal derretido a entrar nos moldes utilizados nas suas fundiçóes em molde tradicional, eliminando o ar que normalmente torna as peças metálicas porosas (Tidd, J., Bessant, J. \& Pavitt, K., 2003, p. 266).

Em Portugal, temos os exemplos das empresas Hovione, Generis, Farmoz (Tecnimede), Labesfal, Ratiopharma e Almus que consultam a Informação de Patentes para saber que patentes irão caducar e permitirão o fabrico de medicamentos genéricos. Temos, também, o exemplo do 'Forno Solar' desenvolvido por Manuel Colares Pereira ${ }^{11}$ (Professor no IST e Investigador no INETI) com base numa patente, já caducada, de um invento semelhante (o Pirelióforo do Padre Mag Himalaya) mas usado para outras funçôes (fundir metais) ${ }^{12}$.

Todos os exemplos apresentados levam-nos a concluir que, a eficaz utilizaçáo deste tipo de informaçáo pode realmente traduzir-se numa fonte incalculável de vantagens competitivas para os utilizadores que dela saibam retirar o conhecimento que implicitamente contém e as integrem em posteriores aplicaçôes que os conduzam a uma situação vantajosa nos mercados em que actuam.

\section{2 - Bibliotecas Digitais de patentes}

\section{1 - Definição de Biblioteca Digital}

Começaremos a nossa exposição explicando o que é uma Biblioteca Digital (BD), quais as suas vantagens e porque se torna imperiosa a sua existência para o tema em análise: a Informação de Patentes.

Assim, "uma biblioteca digital é, sobretudo, uma construção intelectual ou lógica capaz de reunir um todo estruturado a partir de uma grande variedade de recursos" (Borges, M., 2002, p. 160). Ou, dito de outra forma,

"A digital library means an institution or a mechanism which offers masses of digital information to end users over the network, andlor assist the end-users to retrieve necessary information from there, including those institutions where books, journals and other large body of information are created, collected and converted, or edited to form a large digital database to serve request over the network" (Yamamoto, T., 1997, p. 38).

De acordo com Maria Manuel Borges (2002, p. 156) "a mais valia da biblioteca digital não reside nas suas colecçóes mas na forma como estas se encontram organizadas e sâo disponibilizadas a todo um conjunto de utilizadores (...)."

11 "FORNO SOLAR CONCENTRADOR DO TIPO CAIXA, INCORPORANDO OTICA DO TIPO COLECTOR PARABOLICO COMPOSTO. Número da Patente: PT102576, Data de publicação: 2002-0930, Inventor: PEREIRA MANUEL (PT); OLIVEIRA JO O (PT), Requerente: SUN CO COMPANHIA DE EN SOLAR S (PT)" (http://pt.espacenet.com/ - 24-12-2004).

12 Programa ‘ 4 X Ciência’, de Andreia Azevedo Soares na TV2 (23-09-2004 - 14 h00 às 15h00). 
Daqui se pode deduzir a importância da existência deste recurso para a área em análise - A literatura de Patentes - uma vez que possibilitam o acesso à informação nelas contida, em inúmeros países onde tais documentos se encontram em formato papel, evitando deslocaçóes onerosas e praticamente impossíveis de realizar.

Se fosse necessário efectuar a deslocação a todos os gabinetes de Propriedade Intelectual (PI) do mundo de modo a verificar se determinado invento se encontra protegido nesse país seria impossível em tempo útil e com recursos escassos proceder a essa verificação. Conforme Arai,

"Under the old system, you had to go to the Patent Office in person. Now you can search the applications and access the latest advances in science and technology by computer from the comfort of your own home. This enables universities, venture start-ups, and other researchers on tight financial and personnel budgets to avoid duplicating research or getting embroiled in patent disputes, and will make it much easier for these institutions to track technology trends effectively (...). The Intellectual Property Digital Library is also expected to change the way that corporations, universities, and other research institutions do their patent work, and it will make a major contribution to the development of science and technology (...)”. (Arai, H., 1999, p. 69)

A importância da $\mathrm{BD}$ na disseminação desse tipo de conhecimento é sem dúvida de extraordinária relevância pela sua actualidade e facilidade no acesso e consulta da "informaçâo" que "é disponibilizada a um conjunto de utilizadores potencialmente global" (Borges, M., 2002, p. 160).

De acordo com Takeo Yamamoto, já citado, as vantagens da existência de uma BD são, nas suas próprias palavras:

"(i) Immutability of the text; (ii) Large repository of electronic information; (iii) Effective tool for bridging the information gap; (iv) Interactive access to the collection; (v) Instant access to the collection; (vi) Distributed knowledge environment; (vii) Fully automated indexing \& intelligent retrieval; (viii) Digital reading and referencing of materials; (ix) Effective image search; (x) Digital preservation; (xi) Reduced space problem; (xii) High update rate" (Yamamoto, T., 1997, p. 39).

A BD "surge-nos assim como uma meta-entidade capaz de aglomerar náo física mas virtualmente os objectos de informação. Caracteriza-se por vários fenómenos entre os quais destacamos a desterritorialização e o de eliminação das categorias espácio-temporais" (Borges, M., 2003, p. 8).

Todos estes motivos justificam e tornam válida a existência de uma BD de Patentes para difusão do saber técnico-científico acumulado ao longo do tempo (Chandra, H., 2002).

\section{2 - Alguns Exemplos de Bibliotecas Digitais de Patentes}

A vantagem dos recursos que passamos a descrever é que, para além de serem gratuitos, bastando um computador com acesso à Internet, permitem consultar informação de registos de patente dos principais países industrializados, com maior número de invençôes e consequentemente de Patentes atribuídas, como também, em certos casos, o acesso aos documentos cujas patentes foram recusadas ou que ainda se encontram em fase de análise. Mesmo recusado o pedido de Patente, a 
informação aí contida é relevante pois inclui o que de mais recente se faz nessa área do saber.

Na Patent Scope da OMPI estão os documentos de Patente pedidos via Tratado PCT (Patent Cooperation Treaty) que possibilita que um único pedido seja válido nos cerca de 130 países que o constituem. A partir de um único ponto temos acesso a cerca de 1,5 milhóes de Patentes internacionais, desde a primeira publicação na sua origem em 1978.

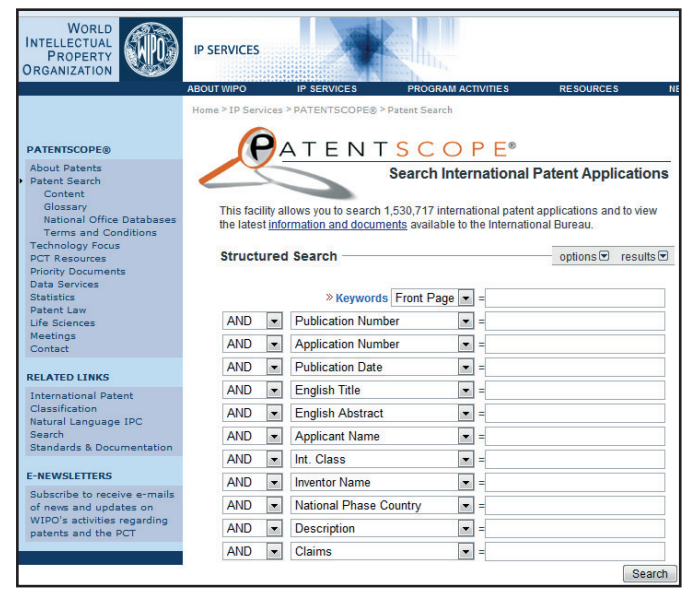

Fig. 1 - Biblioteca Digital do Patent Scope da OMPI (http://www.wipo.int/pctdb/en)

Aquela que talvez seja mais interessante para as empresas portuguesas, uma vez que se encontra em português, o que pode facilitar a sua consulta e utilização é a Esp@cenet. A funcionar desde 1998, contém as Patentes concedidas em Portugal e em todos os países que assinaram o Tratado Europeu de Patentes via EPO. Elaborada com base na anterior, e uma das pioneiras BD de Patentes, a INPADOC, permite o acesso a mais de 60 milhóes de documentos de Patente, provenientes de mais de 75 países.

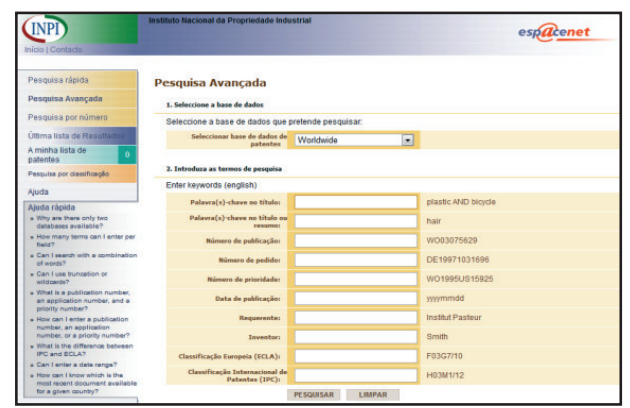

Fig. 2 - Biblioteca Digital de Patentes do Esp@cenet (em Português) (http://pt.espacenet.com) 
Passamos agora ao 'gigante americano', a BD do USPTO. Aqui é possível pesquisar não só os documentos de Patentes concedidas como também das que se encontram em análise. A funcionar desde 1976, possui informação desde 1790. Desde 2001 permite pesquisar os documentos ainda antes da Patente ser concedida. A sua BD é seguramente a maior, considerando um país individualmente.

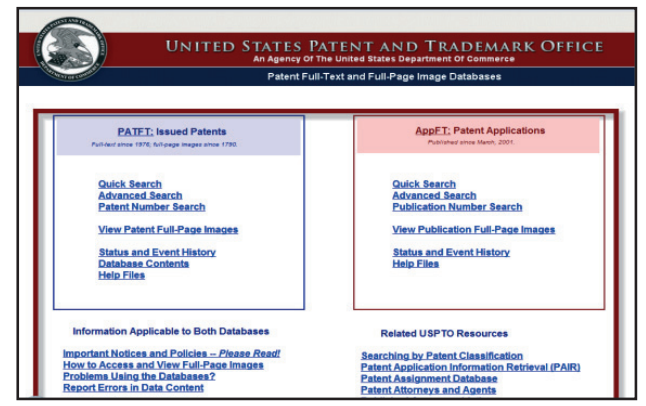

Fig. 3 - Biblioteca Digital de Patentes do USPTO (http://www.uspto.gov)

Igualmente relevante é a BD do acordo Trilateral de Patentes. Sob a alçada do Gabinete Japonês de Patentes, permite o acesso às BD de Patentes do Japão, traduzidas em Inglês, do EPO e do USPTO, a partir de um único interface.

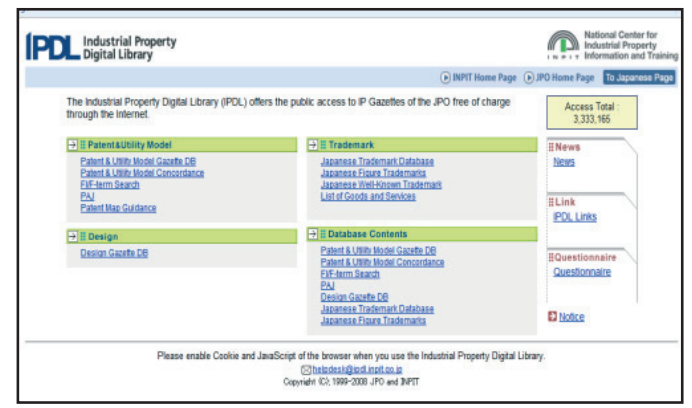

Fig. 4 - Biblioteca Digital do Acordo Trilateral de Patentes (http://www.ipdl.inpit.go.jp/homepg_e.ipdl)

Vários exemplos de países como a China, Coreia do Sul, Singapura, Alemanha e França, entre muitos outros, podem ser encontrados como forma de mostrar a aposta feita na disseminação deste tipo de informação para permitir aos seus concidadãos beneficiarem da consulta da Informação de Patentes.

\section{3 - Patentes de Invenção}

São um direito exclusivo concedido a uma invenção, produto ou processo, que permita uma nova forma de realizar algo ou uma solução técnica nova para resolver um 
problema. ${ }^{13}$ A sua finalidade é incentivar o desenvolvimento económico e tecnológico recompensando a criatividade. Providencia protecção à invençáo, geralmente por um período de tempo limitado, em troca da divulgaçáo pública pelo inventor, da inovaçáo técnica nela contida. É importante lembrar que podem também ser patenteados os processos novos de obtenção de produtos, substâncias ou composições já conhecidos. Conhecer a Informaçáo de Patentes pode permitir o desenvolvimento dos mesmos produtos mas por processos diferentes dos patenteados, originando uma redução nos custos que pode conduzir a vantagens competitivas.

Actualmente, a duração da Patente em Portugal é de 20 anos contados da data do respectivo pedido. Para dispor livremente da tecnologia nelas contida é necessário esperar que a patente caduque por limite temporal, ou por outras razóes como o não pagamento das taxas devidas pela manutençáo anual da patente.

Também de realçar que, podem ser concedidas 'Licenças Obrigatórias' sobre determinada patente, entre outras razóes, sempre que se verifique existir falta ou insuficiência de exploração ${ }^{14}$ da invenção patenteada (Cfr. CPI, 2003 - Secção IV, pp. $94-99$, Art $\left.^{\circ} .105-110\right)$.

\section{1 - Portugal e a Propriedade Industrial}

Estudos recentes realizados para aferir o grau de utilização da Propriedade Industrial (PI) em Portugal, figura jurídica onde se inserem as Patentes, demonstram não só uma fraca utilização da protecção concedida pelas Patentes, como também um desconhecimento generalizado sobre as vantagens decorrentes da consulta da informação que as mesmas veiculam (Roland Berger \& Partner, 1998; Godinho, 2003).

Esta afirmação apoia-se na comparação realizada entre Portugal e vários Países da Organização para a Cooperação e Desenvolvimento Económico (OCDE), relativamente ao investimento em Investigação e Desenvolvimento $(\mathrm{I} \& \mathrm{D})$ e também à proporção de pedidos de Patente efectuados por estrangeiros no nosso País.

Para reforçar esta perspectiva menos optimista, do levantamento realizado para o Estudo Sobre a Utilização da Propriedade Industrial em Portugal, em cerca de 21 anos entre 1980 e 2001, foram efectuados 1.678 pedidos de Patente por residentes recorrendo à via nacional, contra 25.250 efectuados por não-residentes. Desse número de pedidos foram concedidas 565 patentes a residentes contra 17.047 a náo-residentes. (Godinho, 2003, p. 150).

De salientar como um dos resultados deste estudo que a maioria das empresas portuguesas atribui baixa importância à PI (entre $54.0 \%$ e $86.7 \%$, consoante a modalidade).

Comparando com o estudo de 1998 da Roland Berger \& Partner para o INPI podemos deduzir que, na época em que foi realizado, $46 \%$ das empresas industriais

13 Podem ser objecto de patente as invençôes que sejam: a) Novas; b) Impliquem actividade inventiva; c) Sejam susceptíveis de aplicação industrial (CPI, 2003).

14 "In 1974, Xerox's dominant market position was protected by a wall of over 2000 patents, most of which were not used." (GRANT, 2002, p. 238). 
portuguesas, cerca de metade do tecido empresarial, não tinham conhecimento do INPI nem do Sistema de Patentes, "chegando o grau de desconhecimento a atingir quase 60\% nas empresas com menos de 20 trabalhadores" (Roland Berger \& Partner, 1998, p. 12). Inclusive, $80 \%$ das empresas que dizem conhecer o Sistema de Patentes, refere apenas dispor de um conhecimento vago acerca do mesmo. No mesmo estudo também podemos ler que a protecção por Patente náo é considerada como uma vantagem competitiva importante por parte das empresas industriais, continuando estas empresas a sustentar o seu esforço na base do secretismo e da antecipação aos concorrentes "como forma de melhor aproveitarem as suas inovaçóes e de as defenderem" (Roland Berger \& Partner, 1998, p. 13).

Relativamente à utilização da informação técnica contida nas Patentes, apenas $4 \%$ das empresas não-utilizadoras do Sistema de Patentes se serve deste instrumento de monitorização, não sendo as empresas utilizadoras do Sistema muito mais assíduas nesta utilização, com apenas 7\% a "analisar regularmente outras Patentes com o interesse de colher informação sobre novos desenvolvimentos da concorrência” (Roland Berger \& Partner, 1998, p. 15).

Será interessante comparar estes valores com os dos Centros de Investigaçáo em que $30 \%$ dos casos afirmam utilizar regularmente a Informação de Patentes como informação técnica. Daí, no estudo de 2003 podermos constatar que 4 entre os 10 residentes com maior número de pedidos de Patentes nacionais, correspondendo a 14\% da amostra, são Centros de Investigação (sendo 3 deles Universitários) (Godinho, 2003).

Mesmo o Boletim da PI, editado pelo INPI, só é utilizado por 7\% das empresas que utilizam o Sistema de Patentes e por $2 \%$ das que não o utilizam. Assim, "estes números são reveladores do total desinteresse e incapacidade das empresas em aproveitarem as fontes que poderão conter informaçóes com interesse directo para o seu negócio" (Roland Berger \& Partner, 1998, p. 204).

Parece-nos que é por demais evidente que a capacidade de obter e analisar a informação tecnológica e de inovação são condiçôes essenciais à competitividade e, até, à sobrevivência futura das empresas portuguesas.

Parece óbvio que facilmente se retiram algumas consideraçôes provenientes destes resultados, sendo uma delas que o não aproveitamento da informação técnica disponibilizada nos documentos de Patente pode bem ser uma das causas principais desta falta de capacidade de inovação que caracteriza o tecido empresarial e a indústria em geral do País, conforme parece ressaltar dos resultados dos "Inquéritos à Inovação em Portugal". 15

Eventualmente, os cientistas e investigadores portugueses não fazem uso deste importante recurso de informação por desconhecerem as reais vantagens daí decorrentes para o seu trabalho. Afinal, não está ainda disseminada nas Universidades a importância da obtenção e consulta de informação técnica e competitiva para apoio à investigação e à tomada de decisão.

15 "Na verdade, a leitura directa dos resultados daqueles dois inquéritos indica uma diminuição da propensão a inovar por parte da indústria portuguesa, entre os finais da década passada e os meados da presente" (GODINHO, M. M., 1999, p. 239). 
Apesar da redução generalizada no número de pedidos de Patente via PCT, os EUA continuam a liderar com quase metade do total de pedidos a serem realizados pelos seus residentes. Se somarmos a estes dados o facto dos EUA terem no mesmo ano, 2001, uma despesa em I\&D de cerca de $2.5 \%$ do PIB, valor acima dos $2.2 \%$ da média dos Países da OCDE, aliado ao facto de termos conhecimento que as suas mais importantes empresas realmente fazem uso da Informação de Patentes, então para podermos aumentar o índice de inovação e desenvolvimento de novos produtos no nosso País, desde logo um procedimento deve ser tomado em consideração:

\section{- A consulta e eficaz utilização da Informaçáo de Patentes.}

O grau de investimento do País em políticas de I\&D náo pode ser facilmente controlado ou modificado de acordo com a indústria em que estivermos inseridos, mas o acesso à Informação de Patentes não está dependente de meios ou favorecimentos externos. Depende somente da nossa vontade de agir e querer um desempenho melhor para a nossa empresa e consequentemente para o País.

Sabendo que grande percentagem das empresas mais inovadoras a nível mundial, incluindo os gigantes Motorola, Procter \& Gamble, Matsushita, NEC, IBM, Cannon, etc., analisam de forma constante e estruturada a Informação de Patentes (Vigilância Tecnológica) para daí retirar inúmeros proveitos em termos de Inteligência Competitiva (PRESCOTT, J. E.; MILLER, S. H., 2002; GOMES, E.; BRAGA, F., 2002; PORTER, M. E., 1980; 1985), parece-nos que a não utilização deste útil e indispensável instrumento de apoio à $I \& D$ das empresas e indústria em geral pode motivar o fraco índice de inovação tecnológica do País, e que o recurso à sua consulta e utilização pode efectivamente aumentar a capacidade de desenvolvimento de novos produtos e processos conducentes a novas soluçóes técnicas que ampliem a percentagem e o volume de inovaçóes realizadas pelas empresas portuguesas.

\section{Conclusão}

Analisamos a Informação de Patentes e a sua importância para o crescimento económico e obtenção de vantagens competitivas. Citamos vários exemplos da sua utilização estratégica, donde salientamos os seguintes: (i) Usar produtos inventados para uma função mas que adaptados possam servir para outra. ${ }^{16}$ (ii) Conhecer produtos patenteados que possam ser melhorados permitindo o registo de um "Modelo de Utilidade" e tornando-os tecnologicamente mais avançados. (iii) Usar em Portugal produtos e processos que não estejam registados e protegidos no nosso País ou cuja Patente já tenha caído em domínio público (Ex. Medicamentos genéricos - substância activa dos medicamentos cuja patente expirou; Velcro; Nylon; Lycra, Terylene, etc.

Outras estratégias passam por elaborar:

- Produtos Alternativos ou Substitutos - Realizar algo que sirva de alternativa a uma tecnologia (nova ou não), usando outros materiais, processos, tecnologias ou recursos para fazer um produto que vá suprir a mesma necessidade.

16 Existe um produto que é utilizado nos transplantes de órgãos para que o organismo não rejeite o órgão transplantado que não foi inventado com essa função mas, usado, resulta. 
- Produtos ou Serviços Complementares - Fornecimento de produtos ou serviços complementares a uma dada invenção e inovaçáo. Realizar algum produto ou prestar algum serviço que venha a permitir uma mais eficaz utilização ou melhor aproveitamento da invenção original.

- Fundamentação legal - A Informação de Patentes deve ser consultada para descobrir Patentes que não estejam a ser exploradas no País permitindo, assim, requerer uma LICENÇA OBRIGATÓRIA.

Caso exista um produto ou processo patenteado que não esteja a ser explorado pelo seu detentor ou por alguém por ele designado, se houver interesse em proceder a essa exploração pode ser requerida uma LICENÇA OBRIGATÓRIA para o fazer, evitando patentes defensivas.

As Patentes cujas taxas não sejam pagas pelo seu detentor fazem caducar a protecção da Patente, caindo esta em domínio público e podendo assim ser usada livremente.

Concluímos, salientando que esta náo é uma iniciativa que se deva protelar por muito mais tempo, nem tampouco é uma estratégia que sendo implementada vá de imediato resolver os problemas do País. É sim, uma condição essencial a prosseguir para dotar as nossas Organizaçóes e Centros de I\&D das condiçóes básicas necessárias à obtenção de capacidade técnica, capaz de possibilitar o domínio competitivo em áreas-chave de alta e baixa incidência tecnológica.

\section{Referências Bibliográficas}

Arai, H. (1999). Intellectual Property Policies for the Twenty-First Century: The Japanese Experience in Wealth Creation. WIPO Publication No. 834 (E). Retrieved from http://www.wipo.int/ freepublications/en/intproperty/834/index.html (21-08-2009 - 1h57).

Butler, J. T. (1995). Patent Searching Using Commercial Databases. In M. Lechter. (ed.) - Successful Patents and Patenting for Engineers and Scientists (pp. 36-64). New York: IEEE Press.

Borges, M. (1999). A Esfera e a Pirâmide : os (des)lugares da Informação. Revista de História das Ideias. Vol. 20, pp. 495-520.

Borges, M. (2000). A biblioteca tridimensional. Ciberkiosk. Junho 2000. Retrieved from http:// www.ciberkiosk.pt/arquivo/ciberkiosk8/media/biblioteca.html.

Borges, M. (2001). A Biblioteca Digital : da imaginação em exercício ao exercício da imaginação. Páginas a\&b. No 7, pp. 7-67.

Borges, M. (2002). De Alexandria a Xanadu. Coimbra: Quarteto.

Borges, M. (2003). Biblioteca Digital : Materialização e Utopia. Revista da Faculdade de Letras: Ciências e Técnicas do Património. Vol. 2, pp. 653-664.

Cantrell, R. (1997). Patents Intelligence from Legal and Commercial Perspectives. World Patent Information. 19, no 4, pp. 251-264.

Chandra, H. (2002). Digital Library for Patents. Retrieved from http://eprints.rclis.org/4585/1/ naclin.pdf (31-01-2009-3h40).

Ernst, H. (2003). Patent Information for Strategic Technology Management. World Patent Information. 25, pp. 233-242. 
MINISTÉRIO DA ECONOMIA (2001). Estatísticas de Propriedade Industrial : Anuário Estatístico. Lisboa: INPI - Instituto Nacional da Propriedade Industrial. Direcção de Informação e Promoção da Inovação. Departamento de Promoção da Inovação.

MINISTÉRIO DA ECONOMIA (2002). Economia \& Prospectiva: A Propriedade Industrial. No 19, Jan./Mar.: GEPE - Gabinete de Estudos e Prospectiva Económica.

Godinho, M. M. (Coord.) (2003). Estudo Sobre a Utilização da Propriedade Industrial em Portugal. Lisboa: Realizado pelo CISEP/ISEG para o INPI.

Gomes, E. \& Braga, F. (2002). Inteligência Competitiva: Como Transformar Informação em um Negócio Lucrativo. Rio de Janeiro: Campus.

Grant, R. M. (2002). Contemporary Strategy Analysis : Concepts, Techniques, Applications. $4^{a}$ ed., Cornwall: Blackwell.

Idris, K. (2003). Intellectual Property : A Power Tool for Economic Growth. Geneva: World Intellectual Property Organization (WIPO).

Macedo, M. F. G. \& Barbosa, A. L. F. (2000). Patentes, Pesquisa \& Desenvolvimento : Um Manual de Propriedade Intelectual. Rio de Janeiro: Fiocruz.

Marcus, D. C. (1995). Benefits of Using Patent Databases as a Source of Information. In M. Lechter. (ed.). Successful Patents and Patenting for Engineers and Scientists (pp. 65-70). New York: IEEE Press.

MOTIVACTION: RESEARCH AND STRATEGY (2003). Usage Profiles of Patent Information Among Current and Potential Users. Report on the Main Results of the Survey Commissioned by the European Patent Office. Amsterdam, Project Number: G018.

Porter, M. E. (1980). Competitive Strategy : Techniques for Analyzing Industries and Competitors. New York: Free Press.

Porter, M. E. (1985). Competitive Advantage : Creating and Sustaining Superior Performance. New York: Free Press.

Prescott, J. E. \& Miller, S. H. (eds.) (2002). Inteligência Competitiva na Prática: Técnicas e Práticas bem Sucedidas para Conquistar Mercados. Rio de Janeiro: Campus.

Ribeiro, D. (2007). Propriedade Intelectual : Mais de 30\% da investigação em Portugal é redundante. Jornal de Negócios. Quinta-feira, 24 de Maio.

Robson, P. (1998). Promoting the Exploitation of Patents Information : Letting Others do Your Work for You! World Patent Information. 20, pp. 125-128.

Roland Berger \& Partner (1998). Estudo Sobre o Grau de Utilização da Propriedade Industrial em Portugal. Lisboa: INPI.

Slater, P., Twyman, P. \& Blackman, M. (2000). The Smart Way for Patent Information to Help Small Firms. World Patent Information. 22, pp. $337-341$.

Tidd, J., Bessant, J. \& Pavitt, K. (2003). Gestão da Inovação : Integração das Mudanças Tecnológicas, de Mercado e Organizacionais. $1^{\text {a }}$ ed., s/loc: Monitor.

Yamamoto, T. (1997). Conditions for Viable Scholarly Electronic Journals : The Role of Digital Libraries. Proceedings of International Symposium on Research, Development \& Practice in Digital Libraries (ISDL'97), pp. 36-41.

\section{Sítios Web de Referência}

World Intellectual Property Organization - http://www.wipo.int

European Patent Office - http://www.epo.org| http://www.epoline.org 
Instituto Nacional da Propriedade Industrial - http://www.inpi.pt

United States Patent and TradeMark Office - http://www.uspto.gov

Intellectual Property Digital Library - http://ipdl.wipo.int/

Esp@cenet - http://pt.espacenet.com

Micropatent - http://www.micropatent.com

Intellectual Property Office of Singapore - http://www.surfip.gov.sg

Korean Intellectual Property Office - http://www.kipo.go.kr

Korea Institute of Patent Information - http://www.kipris.or.kr

Chemical Abstracts Service - http://www.cas.org

Industrial Property Digital Library - http://www.ipdl.inpit.go.jp/homepg_e.ipdl

Intellectual Property Office of P. R. China - http://www.sipo.gov.cn

German patent information system - http://depatisnet.de

Delphion Intellectual Property Network - http://www.delphion.com/

Derwent World Patents Index - http://thomsonreuters.com/products_services/scientific/

DWPI 